\title{
Commentary: Revisiting old data: Is video-assisted thoracoscopic surgery still superior to thoracotomy when enhanced recovery is applied?
}

\author{
David B. Nelson, MD, MSc, ${ }^{a}$ and Mara B. Antonoff, MD, FACS ${ }^{b}$
}

\author{
From the ${ }^{\mathrm{a}}$ Department of Surgery, Loma Linda University Health, Loma Linda, Calif; and ${ }^{\mathrm{b}}$ Department of \\ Thoracic and Cardiovascular Surgery, University of Texas MD Anderson Cancer Center, Houston, Tex. \\ Disclosures: Authors have nothing to disclose with regard to commercial support. \\ Received for publication Aug 29, 2019; revisions received Aug 29, 2019; accepted for publication Aug 29, 2019; \\ available ahead of print Oct 15, 2019. \\ Address for reprints: Mara B. Antonoff, MD, FACS, 1400 Pressler St, Unit 1489, Houston, TX 77030 (E-mail: \\ mbantonoff@mdanderson.org). \\ J Thorac Cardiovasc Surg 2020;159:297-8 \\ 0022-5223/ $\$ 36.00$ \\ Copyright (C) 2019 by The American Association for Thoracic Surgery \\ https://doi.org/10.1016/j.jtcvs.2019.08.095
}

In this well-written article, ${ }^{1}$ Krebs and colleagues present their findings of 130 patients who were treated with either video-assisted thoracoscopic surgery (VATS) or thoracotomy after implementation of an enhanced recovery protocol. They found that, contrary to long-held beliefs, VATS was not associated with either lessened opioid requirements nor improved pain scores. In this cohort, the open operations were more complex, with greater stage disease and increased use of neoadjuvant therapy; however, after risk adjustment, VATS was unexpectedly not associated with either shorter length of stay nor reduced complication rate-again, contrary to long-standing findings in the pre-enhanced recovery era. These results are of critical importance, given the expansion of enhanced recovery programs and the recent publication of Enhanced Recovery after Surgery Society and European Society of Thoracic Surgeons guidelines. ${ }^{2}$ Certainly, if optimization of perioperative care also diminishes the differences in perioperative morbidity between VATS and open approaches, surgeons have greater discretion to select the most appropriate means of access to the chest for any given operation with less concern for long-held beliefs regarding many of the downsides of thoracotomy.

These findings also have important relevance to surgeons who are being faced with increasingly challenging operations. As greater numbers of small, early-stage lung cancers are addressed with nonoperative modalities such as stereotactic body radiation therapy, we surgeons are operating in new spaces that come with their own technical difficulties. We are operating on more patients who have received induction treatment with chemotherapy, immunotherapy, and targeted therapies. Increasing data support the use of surgery in patients with (oligo)metastatic disease, and we are operating in many of these scenarios on patients who have adhesions and nodal sclerosis from innovative

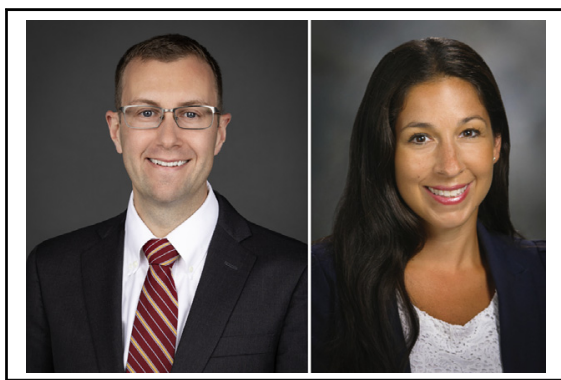

David B. Nelson, MD, MSc (left), and Mara B. Antonoff, MD, FACS (right)

Central Message

Perioperative outcomes between video-assisted thoracoscopic surgery (VATS) and open approaches appear similar when an enhanced recovery program is used.

See Article page 284. systemic treatments. ${ }^{3-5}$ Open approaches can be incredibly helpful in these types of clinical scenarios and to ultimately improve patient outcomes.

This study is limited by power, which is expected, given the relatively recent implementation of enhanced recovery programs. Indeed, it may take some time before such an adequately powered study could be published. However, other centers have been publishing similar findings. At our center, we also found differences in pain scores between VATS and open approaches disappeared once we implemented elements of an enhanced recovery program. ${ }^{6}$ In addition, surgical approach whether VATS or open was not associated with adjuvant chemotherapy completion among patients who were treated under an enhanced recovery pathway, suggesting that the surgical approach was less relevant to predict functional recovery when enhanced recovery is applied. ${ }^{7}$ Rogers and colleagues ${ }^{8}$ also found that the surgical approach, whether by VATS or open, was not associated with perioperative morbidity when an enhanced recovery pathway was used. This chorus of findings should lead us to re-evaluate whether long-standing studies showing improvements in VATS as opposed to an open approach continue to apply in a modern era with optimized perioperative care through enhanced recovery programs. The authors should be commended 
for their well-written paper addressing this important concept.

\section{References}

1. Krebs ED, Mehaffey JH, Sarosiek BM, Blank RS, Lau CL, Martin LW. Is less really more? Reexamining video-assisted thoracoscopic versus open lobectomy in the setting of an enhanced recovery protocol. J Thorac Cardiovasc Surg. 2020;159:284-94.e1.

2. Batchelor TJP, Rasburn NJ, Abdelnour-Berchtold E, Brunelli A, Cerfolio RJ, Gonzalez $\mathrm{M}$, et al. Guidelines for enhanced recovery after lung surgery: recommendations of the enhanced recovery after surgery (ERAS(R)) Society and the European Society of Thoracic Surgeons (ESTS). Eur J Cardiothorac Surg. 2019:55:91-115.

3. Gomez DR, Blumenschein GR Jr, Lee JJ, Hernandez M, Ye R, Camidge DR, et al. Local consolidative therapy versus maintenance therapy or observation for patients with oligometastatic non-small-cell lung cancer without progression after first-line systemic therapy: a multicentre, randomised, controlled, phase 2 study. Lancet Oncol. 2016;17:1672-82.
4. Mitchell KG, Farooqi A, Ludmir EB, Corsini EM, Vaporciyan AA, Swisher SG et al. Improved overall survival with local consolidative therapy in oligometastatic non-small cell lung cancer: results from a cohort of 194 patients with synchronous disease. Int J Radiat Oncol Biol Phys. 2019;104:229.

5. Elamin YY, Antonoff M, Blakely C, Baggstorm M, Bivona T, Le X, et al. 1509TiP Randomized phase II trial of osimertinib with or without local consolidation therapy (LCT) for patients with EGFR-mutant metastatic NSCLC (NORTHSTAR). Ann Oncol. 2018;29(suppl 8).

6. Rice DC, Cata JP, Mena GE, Rodriguez-Restrepo A, Correa AM, Mehran RJ Posterior intercostal nerve block with liposomal bupivacaine: an alternative to thoracic epidural analgesia. Ann Thorac Surg. 2015;99:1953-60.

7. Nelson DB, Mehran RJ, Mitchell KG, Correa AM, Sepesi B, Antonoff MB, et al Enhanced recovery after thoracic surgery is associated with improved adjuvant chemotherapy completion for non-small cell lung cancer. J Thorac Cardiovasc Surg. 2019;158:279-86.e271.

8. Rogers LJ, Bleetman D, Messenger DE, Joshi NA, Wood L, Rasburn NJ, et al. The impact of enhanced recovery after surgery (ERAS) protocol compliance on morbidity from resection for primary lung cancer. J Thorac Cardiovasc Surg. 2018;155:1843-52. 